\title{
Modified non-rectangular hyperbola equation with plant height for photosynthetic light-response curves of Potentilla anserina and Elymus nutans at various growth phases in the Heihe River Basin, Northwest China
}

\author{
LIU Junjie ${ }^{1}$, WANG Xiaoping ${ }^{2}$, RONG Zhanlei ${ }^{1}$, GAO Yunfei ${ }^{1}$, ZHANG Guangde ${ }^{1}$, WANG \\ Wenbin $^{1}$, GE Lijuan ${ }^{1}$, MAO Yahua ${ }^{1}$, GUO Zhaoxia ${ }^{1}$, WANG Qingtao ${ }^{3}$, ZHAO Chuanyan ${ }^{1 *}$ \\ ${ }^{1}$ State Key Laboratory of Grassland Agro-ecosystems, School of Life Sciences, Lanzhou University, Lanzhou 730000, China; \\ ${ }^{2}$ Institute of Arid Meteorology, China Meteorological Administration, Lanzhou 730020, China; \\ ${ }^{3}$ College of landscape and Ecological Engineering, Hebei University of Engineering, Handan 056000, China
}

\begin{abstract}
The non-rectangular hyperbola (NRH) equation is the most popular method that plots the photosynthetic light-response (PLR) curve and helps to identify plant photosynthetic capability. However, the PLR curve can't be plotted well by the NRH equation at different plant growth phases due to the variations of plant development. Recently, plant physiological parameters have been considered into the $\mathrm{NRH}$ equation to establish the modified NRH equation, but plant height $(H)$, an important parameter in plant growth phases, is not taken into account. In this study, $H$ was incorporated into the NRH equation to establish the modified NRH equation, which could be used to estimate photosynthetic capability of herbage at different growth phases. To explore photosynthetic capability of herbage, we selected the dominant herbage species Potentilla anserina L. and Elymus nutans Griseb. in the Heihe River Basin, Northwest China as the research materials. Totally, twenty-four PLR curves and $H$ at different growth phases were measured during the growing season in 2016. Results showed that the maximum net photosynthetic rate and the initial slope of PLR curve linearly increased with $H$. The modified NRH equation, which is established by introducing $H$ and an $H$-based adjustment factor into the NRH equation, described better the PLR curves of $P$. anserina and E. nutans than the original ones. The results may provide an effective method to estimate the net primary productivity of grasslands in the study area.
\end{abstract}

Keywords: plant height; modified non-rectangular hyperbola equation; Potentilla anserina; Elymus nutans; photosynthetic light-response curve; Qilian Mountains

Citation: LIU Junjie, WANG Xiaoping, RONG Zhanlei, GAO Yunfei, ZHANG Guangde, WANG Wenbin, GE Lijuan, MAO Yahua, GUO Zhaoxia, WANG Qingtao, ZHAO Chuanyan. 2019. Modified non-rectangular hyperbola equation with plant height for photosynthetic light-response curves of Potentilla anserina and Elymus nutans at various growth phases in the Heihe River Basin, Northwest China. Journal of Arid Land, 11(5): 764-773. https://doi.org/10.1007/s40333-019-0003-z

\section{Introduction}

The photosynthetic light-response (PLR) curve describes the relationship between the available

\footnotetext{
*Corresponding author: ZHAO Chuanyan (E-mail: nanzhr@1zb.ac.cn)

Received 2018-01-31; revised 2018-10-15; accepted 2019-01-04

(C) Xinjiang Institute of Ecology and Geography, Chinese Academy of Sciences, Science Press and Springer-Verlag GmbH Germany, part of Springer Nature 2019
} 
photosynthetic photon flux density (PPFD) and the leaf net photosynthetic rate $\left(P_{\mathrm{N}}\right)$ (Amanullah, 2015; Noda et al., 2015). The PLR curve is an analytical tool that helps identify the important feature of plant, such as photosynthetic capability. Up to date, numerous models or equation have been constructed to describe it. For example, quadratic polynomial regression model, subsection model, rectangular hyperbola model, non-rectangular hyperbola (NRH) equation, exponential model, modified rectangular hyperbola model and modified exponential model are used to simulate the PLR curve (Thornley, 1976; Farquhar et al., 1980; Marshall and Biscoe, 1980; Kull and Kruijt, 1998; Zufferey et al., 2000; Ye, 2007; Ye et al., 2013; XU et al., 2014; Huntingford et al., 2015). Among these methods, the NRH equation is the most popular one (Prieto et al., 2010; Calama et al., 2013; XU et al., 2014; Mayoral et al., 2015; Zvalinsky and Tishchenko, 2016).

The photosynthetic capability is influenced by PPFD and physiological and morphological features of leaf (Åström et al., 2015; Catoni et al., 2015; Sakoda et al., 2016; Way et al., 2017). The physiological and morphological features of leaf generally include chlorophyll (Chl) content (Walker et al., 1983; Keutgen et al., 1997; Zhu et al., 2012; Gitelson et al., 2015; Khoshbakht et al., 2015; Novichonok et al., 2015; Sawicki et al., 2017; Zhu et al., 2017), water status (Quero et al., 2008; Akhkha, 2010), nitrogen (N) content (Catoni et al., 2015; Onoda et al., 2017), age (Chiarawipa et al., 2012), specific leaf mass (Puglielli et al., 2015, 2016; Xiong et al., 2016) and $\mathrm{CO}_{2}$ concentration (Urban, 2003; Wang et al., 2015, 2017; Smith et al., 2016; Hao et al., 2017). Therefore, modified PLR curves are various due to different environmental conditions of each plant species (Iacono and Sommer, 2010; Lachapelle and Shipley, 2012; Legner et al., 2013; Mu and Fang, 2015; Malerba et al., 2017).

Recently, some researchers are beginning to consider leaf factor into the PLR curve. Ohsumi et al. (2007) incorporated leaf $\mathrm{N}$ content into the equation to calculate the photosynthetic rate of rice leaves. Marino et al. (2010) and Lachapelle and Shipley (2012) established an allometric equation to estimate $P_{\mathrm{N}}$ with specific leaf mass and $\mathrm{N}$ content. Calama et al. (2013) incorporated leaf temperature, soil moisture, and leaf type into the NRH equation and predicted the $P_{\mathrm{N}}$ of pine needles. $\mathrm{Xu}$ et al. (2014) established a modified NRH equation by incorporating $\mathrm{Chl}$ and leaf $\mathrm{N}$ contents to estimate the soil plant analysis development (SPAD) value. However, the determinations of these physiological factors are always destructive and time consuming. We attempted to find a morphological factor to modify the NRH equation to save time and resources. Plant height $(H)$ is a popular indicator to reflect the growth of plants (Ansquer et al., 2009; Muharam et al., 2014; Teh et al., 2015; Xing et al., 2015; Cao et al., 2017; Gleason et al., 2017; Querry and Harper, 2017). However, $H$ is rarely considered in the NRH equation to estimate $P_{\mathrm{N}}$ for grass species.

Potentilla anserina L. and Elymus nutans Griseb. are dominant species of herbages in the Heihe River Basin, Northwest China. The values of net primary productivity (NPP) of the species have received great attention due to development of the livestock industry. Moreover, NPP is closely related to photosynthetic capacity (Malhi et al., 2017). The photosynthetic characteristics of grass are referred to as specific leaf mass, water stress, light condition, leaf $\mathrm{N}$ content, leaf position and $H$. Among these characteristics, $H$ is easily and non-destructively measured and it can represent leaf photosynthetic capacity during the growing season. Thus, our objective is to incorporate $H$ into the NRH equation to establish the modified NRH equation, which can be used to describe the PLR curves of herbage at different growth phases. The results may provide an effective method to estimate the NPP of grasslands in the Heihe River Basin, Northwest China.

\section{Materials and methods}

\subsection{Study area}

The Heihe River, the second largest inland river in the arid region of Northwest China, originated from the Qilian Mountains. Our study area is located in the upper reaches of the Heihe River Basin $\left(38^{\circ} 23^{\prime} 56^{\prime \prime}-38^{\circ} 26^{\prime} 47^{\prime \prime} \mathrm{N}, 9^{\circ} 53^{\prime} 57^{\prime \prime}-99^{\circ} 57^{\prime} 10^{\prime \prime} \mathrm{E}\right)$, covering an area of approximately 12.8 
$\mathrm{km}^{2}$ with an elevation range of 2660-4419 $\mathrm{m}$ a.s.1. Its climate is characterized by short and warm summer and long and cold winter. The annual mean temperature is from $-0.6^{\circ} \mathrm{C}$ to $2.0^{\circ} \mathrm{C}$, and the mean annual precipitation is $435.5 \mathrm{~mm}$. Temperature and precipitation vary with the elevation, i.e., temperature decreases and precipitation increases with increasing elevation. The variation causes a distinct vertical distribution of plant communities from low to high elevation as follows: desert steppe, forest steppe, subalpine shrub and subalpine meadow (Gao et al., 2016).

\subsection{Experiment and measurement}

The study area belongs to subalpine meadow. The dominant species are $P$. anserina and E. nutans. Two $8 \mathrm{~m} \times 8 \mathrm{~m}$ plots, one for $P$. anserina and the other for $E$. nutans, were selected before the growing season in 2016. Each plot was divided into 4 subplots $(4 \mathrm{~m} \times 4 \mathrm{~m})$. A $10 \mathrm{~m}$-wide buffer was designed between two plots as protection from the disturbance of edge effect. The PLR curves of leaf were measured using the Li-6400 portable photosynthesis system (LI-COR Inc., Lincoln, NE, USA) at the early growth phase (15 June), the middle growth phase ( 3 and 22 July) and the late growth phase (15 August) in 2016. In each measurement, the healthy and fully expanded leaves at the middle-upper part of the plant were selected. The selected leaves were measured after $20 \mathrm{~min}$ of illumination at a PPFD of $2000 \mu \mathrm{mol} /\left(\mathrm{m}^{2} \cdot \mathrm{s}\right) . P_{\mathrm{N}}$ was obtained at 14 levels of PPFD (2000, 1800, 1500, 1200, 1000, 800, 600, 400, 200, 150, 100, 50, 20 and 0 $\left.\mu \mathrm{mol} /\left(\mathrm{m}^{2} \cdot \mathrm{s}\right)\right)$ under natural conditions. One subplot was selected at a time to measure the PLR curve for each species. Three PLR curves can be drawn according to the corresponding PPFD of $P_{\mathrm{N}}$. After measuring the PLR curves, $H$ was measured, and 9 replicates were obtained in each subplot. The PLR curve and $H$ were measured 4 times during the growing season, resulting in 24 PLR curves.

\subsection{Development of the modified NRH equation}

Unmodified NRH equation is expressed as follows (Marshall and Biscoe, 1980; Thornley, 1998):

$$
P_{\mathrm{N}}(I)=\frac{\alpha I+P_{\mathrm{N} \max }-\sqrt{\left(\alpha I+P_{\mathrm{N} \max }\right)^{2}-4 \theta \alpha I P_{\mathrm{N} \max }}}{2 \theta}-R_{\mathrm{D}},
$$

where $\alpha$ is the initial slope of the PLR curve $\left(^{\circ}\right) ; I$ is the PPFD $\left(\mu \mathrm{mol} /\left(\mathrm{m}^{2} \cdot \mathrm{s}\right)\right)$; $\theta$ is the convexity of the PLR curve; $P_{\mathrm{Nmax}}$ is the maximum net photosynthetic rate $\left(\mu \mathrm{mol} /\left(\mathrm{m}^{2} \cdot \mathrm{s}\right)\right)$; and $R_{\mathrm{D}}$ is the dark respiration $\left(\mu \mathrm{mol} /\left(\mathrm{m}^{2} \cdot \mathrm{s}\right)\right)$.

Parameters of $\alpha, \theta, P_{\mathrm{Nmax}}$ and $R_{\mathrm{D}}$ were calculated by non-linear least-square fitting. And we developed the modified NRH equation by incorporating $H$ into the equation:

$$
P_{\mathrm{N}}(I)=\beta H \frac{\alpha I+P_{\mathrm{N} \text { max }}-\sqrt{\left(\alpha I+P_{\mathrm{N} \text { max }}\right)^{2}-4 \theta \alpha I P_{\mathrm{N} \text { max }}}}{2 \theta}-R_{D},
$$

where $\beta$ is a coefficient; and $H$ is the height of species $(\mathrm{cm})$. The mean values of $\alpha$ and $P_{\mathrm{Nmax}}$ in the modified NRH equation were used to define $\beta$.

\subsection{Statistical analysis}

We used Sigmaplot (Version 12.5, Systat Software Inc., USA) statistical packages to analyze measurements. The parameters in Equations 1 and 2 were determined by non-linear least-square fitting, which were realized by software $1{ }^{\text {st }}$ Opt (First Optimization; 7D-Soft High Technology Inc., China) using the Levenberg-Marquardt (LM) algorithm. The average absolute error (AE) and the root mean square error (RMSE) were used to assess the performance of the unmodified NRH and the modified NRH equations, and they were calculated as follows:

$$
\begin{gathered}
\mathrm{AE}=\frac{1}{n} \sum_{i=1}^{n}\left|P_{\mathrm{Ncal}, i}-P_{\mathrm{Nobs}, i}\right|, \\
\mathrm{RMSE}=\sqrt{\frac{1}{n} \sum_{i=1}^{n}\left(P_{\mathrm{Ncal}, i}-P_{\mathrm{Nobs}, i}\right)^{2},}
\end{gathered}
$$

where $P_{\mathrm{Ncal}, i}$ is the calculated $P_{\mathrm{N}}$ by Equations 1 and $2\left(\mu \mathrm{mol} /\left(\mathrm{m}^{2} \cdot \mathrm{s}\right)\right) ; P_{\mathrm{Nobs}, i}$ is the observed $P_{\mathrm{N}}$ $\left(\mu \mathrm{mol} /\left(\mathrm{m}^{2} \cdot \mathrm{s}\right)\right)$; and $n$ is the total number of data $(n=336)$. 
The performance of the modified NRH was based on 4 prioritization schemes, that is, Scheme 1: Inputting $P_{\mathrm{N}}$ and PPFD into the modified NRH equation; Scheme 2: Inputting the $\alpha$ limited from 0.03 to 0.08 into the modified NRH equation; Scheme 3: Inputting the maximum values of $P_{\mathrm{Nmax}}$ and $\alpha$ into the modified NRH equation; Scheme 4: Inputting the mean values of $P_{\mathrm{Nmax}}$ and $\alpha$ into the modified NRH equation. According to the measured and estimated photosynthetic parameters, we selected the best scheme.

\section{Results}

\subsection{PLR curves and $\boldsymbol{H}$ at different growth phases}

The PLR curves of $P$. anserina and E. nutans were shown in Figure 1. The mean $P_{\mathrm{N}}$ values were significantly higher in July and August than those in June. The difference in $P_{\mathrm{N}}$ at various growth phases was small when the PPFD was below $500 \mu \mathrm{mol}$ photon $/\left(\mathrm{m}^{2} \cdot \mathrm{s}\right)$, and the difference in $P_{\mathrm{N}}$ increased when the PPFD was above $500 \mu \mathrm{mol}$ photon $/\left(\mathrm{m}^{2} \cdot \mathrm{s}\right)$. Figure 1 showed that the maximum $P_{\mathrm{N}}$ values of $P$. anserina on 15 June and 15 August were 11.54 and $26.71 \mu \mathrm{mol} \mathrm{CO} \mathrm{CO}_{2} /\left(\mathrm{m}^{2} \cdot \mathrm{s}\right)$, and the maximum $P_{\mathrm{N}}$ values of $E$. nutans on 15 June and 15 August were 12.17 and $18.03 \mu \mathrm{mol}$ $\mathrm{CO}_{2} /\left(\mathrm{m}^{2} \cdot \mathrm{s}\right)$, respectively. The variation in $H$ with time of the two species was shown in Figure 2. The maximum and minimum $H$ values for $P$. anserina were 16.62 and $6.13 \mathrm{~cm}$ and those for $E$. nutans were 68.99 and $36.09 \mathrm{~cm}$, respectively. Moreover, as shown below, high $H$ corresponded with high $P_{\mathrm{N}}$ rate.

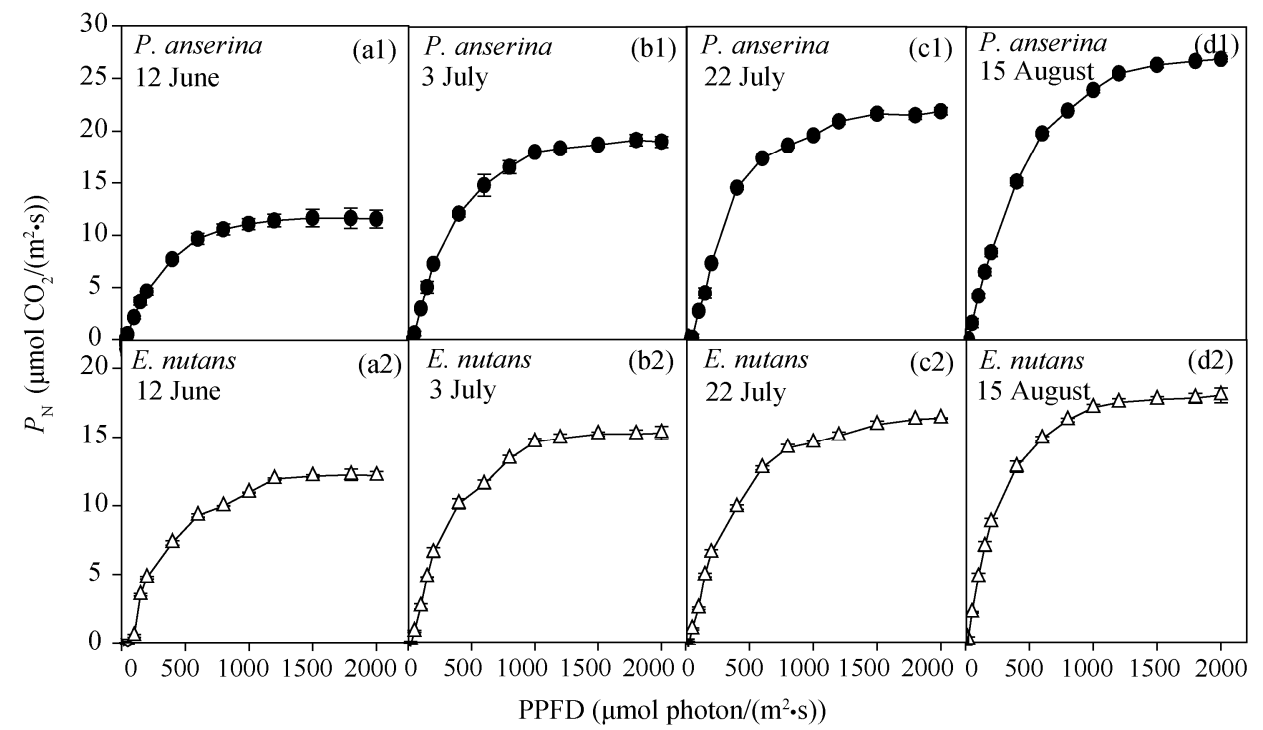

Fig. 1 Net photosynthetic rate $\left(P_{\mathrm{N}}\right)$ response to available photosynthetically photon flux density (PPFD) for the leaves at various growth phases in 2016. Bars mean standard errors; $n=3$.

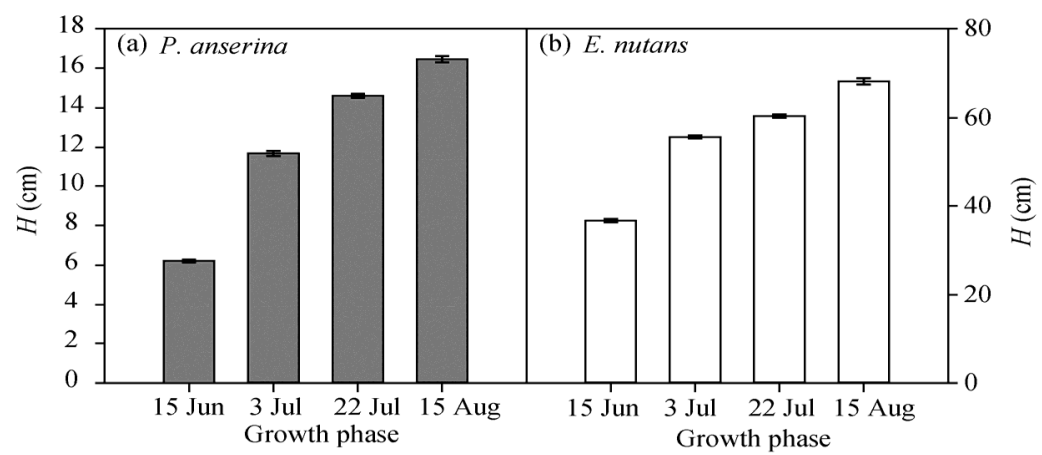

Fig. 2 Variation of plant height $(H)$ values of the two species at various growth phases in 2016. Bars mean standard errors; $n=9$. 


\subsection{Relationship between parameters of the NRH equation and $H$}

For each PLR curve, the NRH equation fitted very well, because photoinhibition of plant species was not found (Fig. 1). The parameters of the NRH equation varied with the changes of $H$ at different growth phases. By analyzing the relationship between photosynthetic parameters in Equation 1 and $H$, we found that two photosynthetic parameters (i.e., $\alpha$ and $P_{\text {Nmax }}$ ) increased linearly with $H$. And the linear relationships were significant at the 0.99 confidence level. Furthermore, the parameters of $\theta$ and $R_{\mathrm{D}}$ were not significantly related to $H$ (Fig. 3).

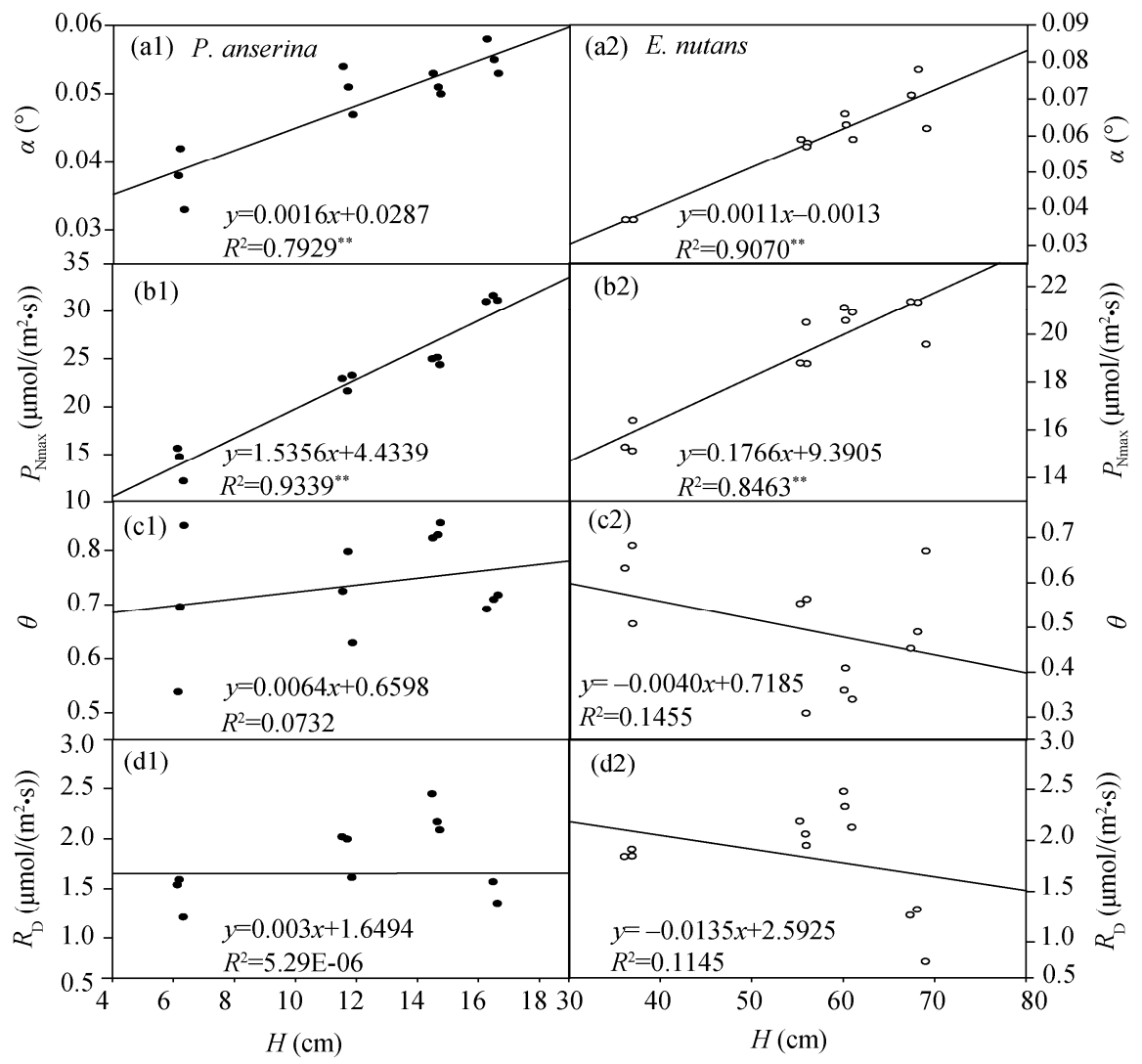

Fig. 3 Relationships between plant height $(H)$ and photosynthetic parameters $\left(\alpha, P_{\mathrm{Nmax}}, \theta\right.$ and $\left.R_{\mathrm{D}}\right)$ in the NRH (non-rectangular hyperbola) equation. ${ }^{* *}$ indicates the significance at $P<0.01$ level. $\alpha$, initial slope of the PLR curve; $P_{\text {Nmax }}$, maximum net photosynthetic rate; $\theta$, convexity of the PLR curve; $R_{\mathrm{D}}$, dark respiration.

\subsection{Performance of the unmodified and modified NRH equations}

Comparing the values of observed and estimated photosynthetic parameters, we found that Scheme 4 (i.e., inputting the mean values of $P_{\mathrm{Nmax}}$ and $\alpha$ into the modified NRH) was the best because the values of parameters really reflected the growing process of the two species (Table 1). Moreover, the mean values of $P_{\mathrm{Nmax}}$ and $\alpha$ are similar to those of the modified NRH equation in Scheme 4 (Table 2). Therefore, mean values of $P_{\text {Nmax }}$ and $\alpha$ were selected to run the modified PLR curves. For $P$. anserina, the values of $0.0488^{\circ}(\alpha)$ and $23.2359 \mu \mathrm{mol} /\left(\mathrm{m}^{2} \cdot \mathrm{s}\right)\left(P_{\mathrm{Nmax}}\right)$ were set as the mean values for the 12 PLR curves, while $0.0572^{\circ}(\alpha)$ and $19.1421 \mu \mathrm{mol} /\left(\mathrm{m}^{2} \cdot \mathrm{s}\right)\left(P_{\mathrm{Nmax}}\right)$ were set for $E$. nutans (Table 2). Values of $\theta, R_{\mathrm{D}}$, and $\beta$ in Scheme 4 for $P$. anserine were determined as $0.7089,0.8436 \mu \mathrm{mol} /\left(\mathrm{m}^{2} \cdot \mathrm{s}\right)$ and 0.0767 , respectively, while for $E$. nutans they were $0.4749,1.2876$ $\mu \mathrm{mol} /\left(\mathrm{m}^{2} \cdot \mathrm{s}\right)$ and 0.0172 , respectively (Table 1$)$. Moreover, we found that the performance of the modified NRH equation performed better than that of the unmodified NRH equation with a higher $R^{2}$ value (Fig. 4). 
Table 1 Values of parameters from different prioritization schemes by the $1^{\text {st }}$ Opt (First Optimization) software with Levenberg-Marquardt algorithm for P. anserina and E. nutans

\begin{tabular}{|c|c|c|c|c|c|c|}
\hline \multirow{2}{*}{ Species } & \multirow{2}{*}{ Parameter } & \multirow{2}{*}{$\begin{array}{c}\text { Unmodified } \\
\text { NRH }\end{array}$} & \multicolumn{4}{|c|}{ Modified NRH equation } \\
\hline & & & Scheme 1 & Scheme 2 & Scheme 3 & Scheme 4 \\
\hline \multirow{8}{*}{$\begin{array}{c}P . \\
\text { anserina }\end{array}$} & $\theta$ & 0.7453 & 0.8643 & 0.8643 & 0.8150 & 0.7089 \\
\hline & $R_{\mathrm{D}}\left(\mu \mathrm{mol} /\left(\mathrm{m}^{2} \cdot \mathrm{s}\right)\right)$ & 1.7223 & 0.2926 & 0.2926 & 0.5287 & 0.8436 \\
\hline & $P_{\mathrm{N} \max }\left(\mu \mathrm{mol} /\left(\mathrm{m}^{2} \cdot \mathrm{s}\right)\right)$ & 23.1512 & 2.7814 & 18.6565 & 31.6580 & 23.2360 \\
\hline & $\alpha\left({ }^{\circ}\right)$ & 0.0483 & 0.0046 & 0.0311 & 0.0580 & 0.0488 \\
\hline & RMSE & 3.5513 & 1.3235 & 1.3235 & 1.3411 & 1.4148 \\
\hline & $\mathrm{AE}$ & 2.3748 & 1.1063 & 1.1063 & 1.1178 & 1.1733 \\
\hline & $R^{2}$ & 0.8377 & 0.9775 & 0.9775 & 0.9769 & 0.9742 \\
\hline & $\beta$ & - & 0.6100 & 0.0909 & 0.0546 & 0.0767 \\
\hline \multirow{8}{*}{ E. nutans } & $\theta$ & 0.5123 & 0.6488 & 0.6488 & 0.1044 & 0.4749 \\
\hline & $R_{\mathrm{D}}\left(\mu \mathrm{mol} /\left(\mathrm{m}^{2} \cdot \mathrm{s}\right)\right)$ & 1.8234 & 0.9835 & 0.9835 & 1.6033 & 1.2876 \\
\hline & $P_{\mathrm{Nmax}}\left(\mu \mathrm{mol} /\left(\mathrm{m}^{2} \cdot \mathrm{s}\right)\right)$ & 19.0431 & 0.3028 & 11.8002 & 21.3590 & 19.1421 \\
\hline & $\alpha\left(^{\circ}\right)$ & 0.0562 & 0.0008 & 0.0300 & 0.0782 & 0.0572 \\
\hline & RMSE & 1.7629 & 1.0400 & 1.0400 & 1.1179 & 1.0587 \\
\hline & $\mathrm{AE}$ & 1.3273 & 0.8100 & 0.8100 & 0.8281 & 0.8058 \\
\hline & $R^{2}$ & 0.9269 & 0.9746 & 0.9746 & 0.9706 & 0.9737 \\
\hline & $\beta$ & - & 1.0501 & 0.0269 & 0.0162 & 0.0172 \\
\hline
\end{tabular}

Note: $\theta$, convexity of the PLR curve; $R_{\mathrm{D}}$, dark respiration; $P_{\mathrm{Nmax}}$, maximum net photosynthetic rate; $\alpha$, initial slope of the PLR curve; RMSE, root mean square error; AE, absolute error; $R^{2}$, coefficient of determination; $\beta$, coefficient. "-" means no value. NRH, non-rectangular hyperbola. The four schemes are presented in Section 2.4 .

Table 2 Parameters variations in the means, unmodified and modified equations for P. anserina and E. nutans

\begin{tabular}{ccccc}
\hline Species & Parameter & Mean & Unmodified NRH equation & Modified NRH equation \\
\hline \multirow{3}{*}{ P. anserina } & $\alpha\left(^{\circ}\right)$ & $0.0488 \pm 0.0071$ & 0.0483 & 0.0488 \\
& $P_{\mathrm{N} \max }\left(\mu \mathrm{mol} /\left(\mathrm{m}^{2} \cdot \mathrm{s}\right)\right)$ & $23.2359 \pm 6.1576$ & 23.1512 & 23.2359 \\
& $\theta$ & $0.7384 \pm 0.0914$ & 0.7452 & 0.7089 \\
\hline \multirow{2}{*}{ E. nutans } & $R_{\mathrm{D}}\left(\mu \mathrm{mol} /\left(\mathrm{m}^{2} \cdot \mathrm{s}\right)\right)$ & $1.6535 \pm 0.5493$ & 1.7223 & 0.8436 \\
& $\alpha\left(^{\circ}\right)$ & $0.0574 \pm 0.0129$ & 0.0562 & 0.0574 \\
& $P_{\mathrm{N} \max }\left(\mu \mathrm{mol} /\left(\mathrm{m}^{2} \cdot \mathrm{s}\right)\right)$ & $9.1421 \pm 2.2305$ & 19.0431 & 0.1421 \\
& $\theta$ & $0.4974 \pm 0.1220$ & 0.5123 & 0.4750 \\
\hline
\end{tabular}

Note: $\alpha$, initial slope of the PLR curve; $P_{\mathrm{Nmax}}$, maximum net photosynthetic rate; $\theta$, convexity of the PLR curve; $R_{\mathrm{D}}$, dark respiration; Mean \pm SD; $n=12$.

\section{Discussion}

The NRH equation describes the relationship between $P_{\mathrm{N}}$ and PPFD (Mayoral et al., 2015; Zvalinsky and Tishchenko, 2016), which is popular for expressing the PLR curves. However, it is laborious and time consuming to estimate photosynthetic capability (Xu et al., 2014). A lot of studies have depicted photosynthetic characteristics of species on the diurnal scale (Belshe et al., 2008; Orujova et al., 2018), few studies reported photosynthetic characteristics on the seasonal scale (Proietti and Famiani, 2002; Gao et al., 2015). However, estimate of $P_{\mathrm{N}}$ depended on limited measurements cannot represent the photosynthetic capability during plant growth phases. Therefore, studies have tried to estimate the trend of photosynthetic capability by measuring biological factors and combining with parameters in the NRH equation (Ohsumi et al., 2007; Lachapelle and Shipley, 2012). In this way, $P_{\mathrm{N}}$ could be interpolated during growth season, and the accuracy of $P_{\mathrm{N}}$ estimated would be improved. 


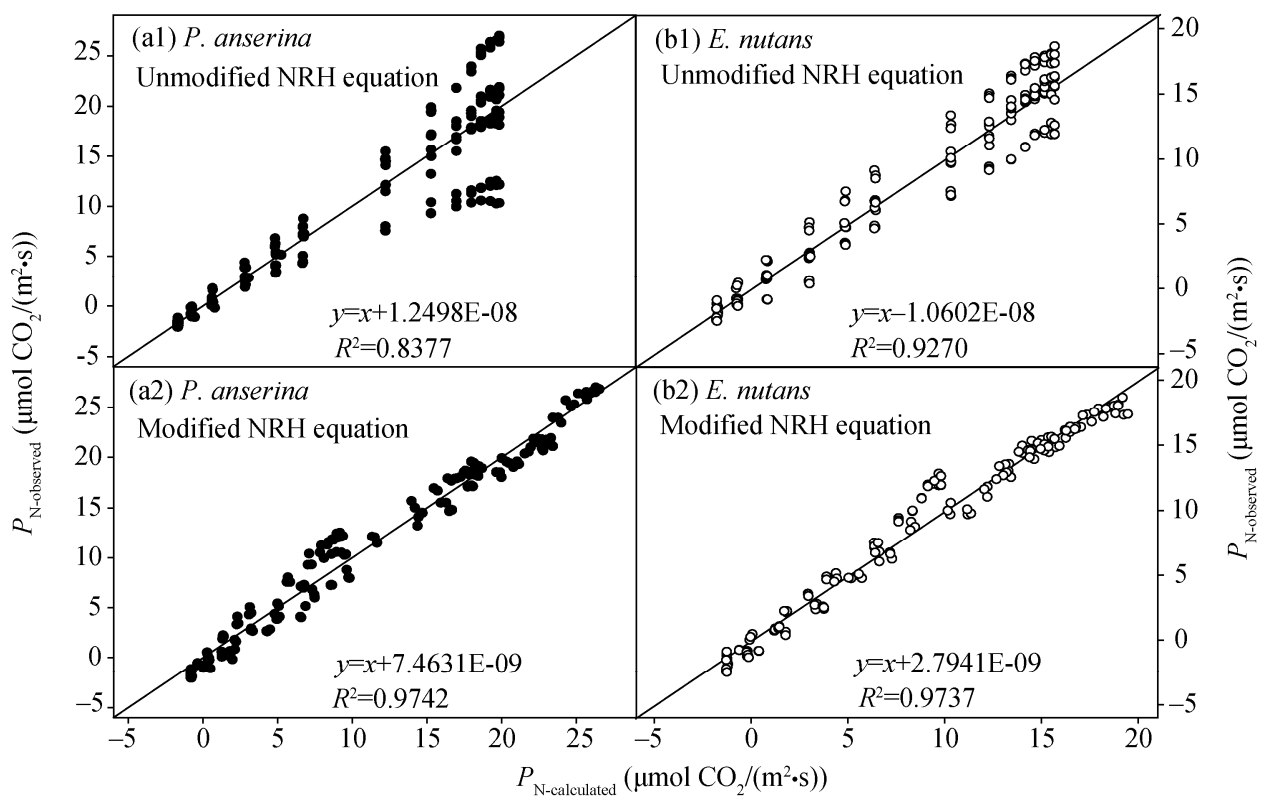

Fig. 4 Relationships between observed $\left(P_{\mathrm{N}-\text { observed }}\right)$ and calculated $P_{\mathrm{N}}\left(P_{\mathrm{N}-\text { calculated }}\right)$ values. $\mathrm{NRH}$, non-rectangular hyperbola.

Four parameters (i.e., $\alpha, \theta, P_{\mathrm{Nmax}}$ and $R_{\mathrm{D}}$ ) in the NRH equation are generally obtained by fitting of measured PLR curve. Several group values of $\alpha, \theta, P_{\mathrm{Nmax}}$ and $R_{\mathrm{D}}$ were derived according to measuring methods. If the correlation between parameters and biological factors was low, the range of parameters could be selected, otherwise, certain values were selected (Marino et al., 2010; Xu et al., 2014). For example, Marino et al. (2010) selected the certain values of $P_{\mathrm{Nmax}}$ and $R_{\mathrm{D}}$ to input the NRH equation, but Xu et al. (2014) selected the ranges of $\theta$ and $R_{\mathrm{D}}$ to input the NRH equation. We selected the ranges of $\theta$ and $R_{\mathrm{D}}$, and certain values of $\alpha$ and $P_{\mathrm{Nmax}}$ in the study. Regarding $\alpha$ and $P_{\text {Nmax }}, \mathrm{Xu}$ et al. (2014) directly selected the maximum values of $\alpha$ and $P_{\text {Nmax }}$ to run the SPAD-NRH equation. After analyzing the 4 schemes, we chose the mean values of $\alpha$ and $P_{\text {Nmax }}$ to the modified PLR curves, which really reflected the growing process of the two species.

Easily measured factors such as $H$, leaf $\mathrm{Chl}$ content, $\mathrm{N}$ content, leaf water content and leaf special mass are highly related to photosynthetic capability (Akhkha, 2010; Scartazza et al., 2016; Bielczynski et al., 2017; Husen, 2017). Therefore, leaf Chl content, N content, leaf water content and specific leaf mass have been introduced into the NRH equation to improve the accuracy of estimation (Marino et al., 2010; Xu et al., 2014). Comparatively, $H$ can be measured more easily and non-destructively. In our study, we attempt to introduce $H$ into the NRH equation to develop a new equation, that is, the modified $\mathrm{NRH}$ equation. The modified $\mathrm{NRH}$ equation has two advantages. On one hand, it had a better performance compared to the unmodified NRH equation. On the other hand, it overcame the shortcoming of the unmodified PLR curves, which is time and labor consuming.

The performance of the modified NRH equation is also better than that of the SPAD-NRH equation $\left(R^{2}=0.9686 ; n=10\right)$, in which the parameters are calculated using the $\mathrm{Chl}$ and $\mathrm{N}$ contents of leaf (Xu et al., 2014). Thus, $H$ can estimate the $P_{\mathrm{N}}$ of plants better because $P_{\mathrm{N}}$ can be simulated throughout growing season. Furthermore, this method is easy to apply because its parameters can be easily obtained. Consequently, it is more useful for describing photosynthetic responses under different growing conditions.

\section{Conclusions}

The PLR curves and parameters of herbage in the NRH equation changed with different values of $H$. In the NRH equation, $\alpha$ and $P_{\mathrm{Nmax}}$ increased linearly with $H$. The modified NRH equation is 
established by multiplying the linear adjustment factor and $H(\beta \times H)$ in the NRH equation. The modified NRH equation has an advantage over the unmodified NRH equation in terms of accuracy. The performance of the modified NRH equation should be further validated by measuring more PLR curves using different species and growing phases. The study of combining the corresponding environmental factors into the NRH equation would extrapolate to other species or locations.

\section{Acknowledgements}

The research was funded by the National Natural Science Foundation of China $(91025015,51178209)$ and the Project of Arid Meteorological Science Research Foundation of China Meteorological Administration (IAM201608).

\section{References}

Akhkha A. 2010. Modelling photosynthetic light-response curve in Calotropis procera under salinity or water deficit stress using non-linear models. Journal of Taibah University for Sciences, 3: 49-57.

Amanullah. 2015. Specific leaf area and specific leaf weight in small grain crops wheat, rye, barley, and oats differ at various growth stages and NPK source. Journal of Plant Nutrition, 38(11): 1694-1708.

Ansquer P, Duru M, Theau J P, et al. 2009. Functional traits as indicators of fodder provision over a short time scale in species-rich grasslands. Annals of Botany, 103(1): 117-126.

Åström H, Metsovuori E, Saarinen T, et al. 2015. Morphological characteristics and photosynthetic capacity of Fragaria vesca L. winter and summer leaves. Flora, 215: 33-39.

Belshe E F, Durako M J, Blum J E. 2008. Diurnal light curves and landscape-scale variation in photosynthetic characteristics of Thalassia testudinum in Florida Bay. Aquatic Botany, 89(1): 1-22.

Bielczynski L W, Lącki M K, Hoefnagels I, et al. 2017. Leaf and plant age affects photosynthetic performance and photoprotective capacity. Plant Physiology, 175(4): 1634-1648.

Calama R, Puértolas J, Madrigal G, et al. 2013. Modeling the environmental response of leaf net photosynthesis in Pinus pinea L. natural regeneration. Ecological Modelling, 251: 9-21.

Cao Y, Li S, He X, et al. 2017. Mapping QTLs for plant height and flowering time in a Chinese summer planting soybean RIL population. Euphytica, 213(2): 213-239.

Catoni R, Granata M U, Sartori F, et al. 2015. Corylus avellana responsiveness to light variations: morphological, anatomical, and physiological leaf trait plasticity. Photosynthetica, 53(1): 1-12.

Chiarawipa R, Wang Y, Zhang X Z, et al. 2012. Modeling light acclimation of photosynthetic response in different ages of vine leaves. Acta Horticulturae, 956: 255-260.

Farquhar G D, Von Caemmerer S, Berry J A. 1980. A biochemical model of photosynthetic $\mathrm{CO}_{2}$ assimilation in leaves of $\mathrm{C}_{3}$ species. Planta, 149(1): 78-90.

Gao C C, Zhao C Y, Wang C, et al. 2016. Soil physicochemical properties and infiltration characteristics under different vegetation types in Tianlaochi watershed in the upstream of Heihe River. Journal of Soil and Water Conservation, 30(1): 117, 121, 126. (in Chinese)

Gao Z J, Xu B C, Wang J, et al. 2015. Diurnal and seasonal variations in photosynthetic characteristics of switchgrass in semiarid region on the Loess Plateau of China. Photosynthetica, 53(4): 489-498.

Gitelson A A, Keydan G P, Merzlyak M N. 2015. Three-band model for noninvasive estimation of chlorophyll, carotenoids, and anthocyanin contents in higher plant leaves. Geophysical Research Letters, 33(11): 431-433.

Gleason S M, Stephens A E A, Tozer W C, et al. 2017. Shoot growth of woody trees and shrubs is predicted by maximum plant height and associated traits. Functional Ecology, 32(2): 247-259.

Hao X Y, Li P, Li H Y, et al. 2017. Elevated $\mathrm{CO}_{2}$ increased photosynthesis and yield without decreasing stomatal conductance in broomcorn millet. Photosynthetica, 55(1): 176-183.

Huntingford C, Smith D M, Davies W J, et al. 2015. Combining the ABA and net photosynthesis-based model equations of stomatal conductance. Ecological Modelling, 300: 81-88.

Husen A. 2017. Growth characteristics, physiological and metabolic responses of teak (Tectona grandis Linn. f.) clones differing in rejuvenation capacity subjected to drought stress. Silvae Genetica, 59(2-3): 124-136.

Iacono F, Sommer K J. 2010. Response of electron transport rate of water stress-affected grapevines: influence of leaf age. Vitis, 39(4): 137-144. 
Keutgen N, Chen K, Lenz F. 1997. Responses of strawberry leaf photosynthesis, chlorophyll fluorescence and macronutrient contents to elevated $\mathrm{CO}_{2}$. Journal of Plant Physiology, 150(4): 395-400.

Khoshbakht D, Ramin A A, Baninasab B. 2015. Effects of sodium chloride stress on gas exchange, chlorophyll content and nutrient concentrations of nine citrus rootstocks. Photosynthetica, 53(2): 241-249.

Kull O, Kruijt B. 1998. Leaf photosynthetic light response: a mechanistic model for scaling photosynthesis to leaves and canopies. Functional Ecology, 12(5): 767-777.

Lachapelle P P, Shipley B. 2012. Interspecific prediction of photosynthetic light response curves using specific leaf mass and leaf nitrogen content: effects of differences in soil fertility and growth irradiance. Annals of Botany, 109: 1149-1157.

Legner N, Fleck S, Leuschner C. 2013. Low light acclimation in five temperate broad-leaved tree species of different successional status: the significance of a shade canopy. Annals of Forest Science, 70(6): 557-570.

Lin Z H, Zhong Q S, Chen C S, et al. 2016. Carbon dioxide assimilation and photosynthetic electron transport of tea leaves under nitrogen deficiency. Botanical Studies, 57(1): 37-49.

Malerba M E, White C R, Marshall D J. 2017. Phytoplankton size-scaling of net-energy flux across light and biomass gradients. Ecology, 98(12): 3106-3115.

Malhi Y, Girardin C A, Goldsmith G R, et al. 2017. The variation of productivity and its allocation along a tropical elevation gradient: a whole carbon budget perspective. New Phytologist, 214(3): 1019-1032.

Marino G, Aqil M, Shipley B. 2010. The leaf economics spectrum and the prediction of photosynthetic light-response curves. Functional Ecology, 24(2): 263-272.

Marshall B, Biscoe P V. 1980. A model for $\mathrm{C}_{3}$ leaves describing the dependence of net photosynthesis on irradiance. Journal of Experimental Botany, 31(120): 29-39.

Mayoral C, Calama R, Sánchez-González M, et al. 2015. Modelling the influence of light, water and temperature on photosynthesis in young trees of mixed Mediterranean forests. New Forests, 46(4): 485-506.

Muharam F M, Bronson K F, Maas S J, et al. 2014. Inter-relationships of cotton plant height, canopy width, ground cover and plant nitrogen status indicators. Field Crops Research, 169: 58-69.

Noda H M, Muraoka H, Nasahara K N, et al. 2015. Phenology of leaf morphological, photosynthetic, and nitrogen use characteristics of canopy trees in a cool-temperate deciduous broadleaf forest at Takayama, central Japan. Ecological Research, 30(2): 247-266.

Novichonok E V, Novichonok A O, Kurbatova J A, et al. 2015. Use of the at LEAF+ chlorophyll meter for a nondestructive estimate of chlorophyll content. Photosynthetica, 54(1): 1-8.

Ohsumi A, Hamasaki A, Nakagawa $\mathrm{H}$, et al. 2007. A model explaining genotypic and ontogenetic variation of leaf photosynthetic rate in rice (Oryza sativa) based on leaf nitrogen content and stomatal conductance. Annals of Botany, 99(2): $265-273$.

Onoda Y, Wright I J, Evans J R, et al. 2017. Physiological and structural tradeoffs underlying the leaf economics spectrum. New Phytologist, 214(4): 1447-1463.

Orujova T Y, Bayramov S M, Gurbanova U A, et al. 2018. Diurnal temperature-related variations in photosynthetic enzyme activities of two $\mathrm{C}_{4}$ species of Chenopodiaceae grown in natural environment. Photosynthetica, 56(4): 1107-1112.

Prieto J A, Giorgi E G, Peña J P. 2010. Modelling photosynthetic-light response on Syrah leaves with different exposure. Vitis, 49(3): 145-146.

Proietti P, Famiani F. 2002. Diurnal and seasonal changes in photosynthetic characteristics in different olive (Olea europaea L.) cultivars. Photosynthetica, 40(2): 171-176.

Puglielli G, Crescente M F, Frattaroli A R, et al. 2015. Leaf mass per area (LMA) as a possible predictor of adaptive strategies in two species of Sesleria (Poaceae): analysis of morphological, anatomical and physiological leaf traits. Annales Botanici Fennici, 52(1-2): 135-143.

Puglielli G, Varone L, Gratani L, et al. 2016. Specific leaf area variations drive acclimation of Cistus salvifolius in different light environments. Photosynthetica, 55(1): 1-11.

Querry N D, Harper K A. 2017. Structural diversity as a habitat indicator for endangered lakeshore flora using an assemblage of common plant species in Atlantic Canada. Plant Ecology, 218(11-12): 1339-1353.

Sakoda K, Tanaka Y, Long S P, et al. 2016. Genetic and physiological diversity in the leaf photosynthetic capacity of soybean. Crop Science, 56(5): 2731-2741.

Sawicki M, Courteaux B, Rabenoelina F, et al. 2017. Leaf vs. inflorescence: differences in photosynthetic activity of grapevine. Photosynthetica, 55(1): 58-68.

Scartazza A, Baccio D D, Bertolotto P, et al. 2016. Investigating the European beech (Fagus sylvatica L.) leaf characteristics along the vertical canopy profile: leaf structure, photosynthetic capacity, light energy dissipation and photoprotection 
mechanisms. Tree Physiology, 36(9): 1060-1076.

Smith R A, Lewis J D, Ghannoum O, et al. 2016. Leaf structural responses to pre-industrial, current and elevated atmospheric $\mathrm{CO}_{2}$ and temperature affect leaf function in Eucalyptus sideroxylon. Functional Plant Biology, 39(4): 285-296.

Teh C Y, Mahmood M, Shaharuddin N A, et al. 2015. In vitro rice shoot apices as simple model to study the effect of $\mathrm{NaCl}$ and the potential of exogenous proline and glutathione in mitigating salinity stress. Plant Growth Regulation, 75(3): 771-781.

Thornley J H M. 1998. Dynamic model of leaf photosynthesis with acclimation to light and nitrogen. Annals of Botany, 81(3): 421-430.

Urban O. 2003. Physiological impacts of elevated $\mathrm{CO}_{2}$ concentration ranging from molecular to whole plant responses. Photosynthetica, 41(1): 9-20.

Walker D A, Sivak M N, Prinsley R T, et al. 1983. Simultaneous measurement of oscillations in oxygen evolution and chlorophyll a fluorescence in leaf pieces. Plant Physiology, 73(3): 542-549.

Wang M, Xie B, Fu Y, et al. 2015. Effects of different elevated $\mathrm{CO}_{2}$ concentrations on chlorophyll contents, gas exchange, water use efficiency, and PSII activity on $\mathrm{C}_{3}$ and $\mathrm{C}_{4}$ cereal crops in a closed artificial ecosystem. Photosynthesis Research, 126(2-3): 351-362.

Wang X, Wang W, Huang J, et al. 2017. Diffusional conductance to $\mathrm{CO}_{2}$ is the key limitation to photosynthesis in salt-stressed leaves of rice (Oryza sativa). Physiologia Plantarum, 163(1): 45-58.

Wang X Y, Xu X M, Cui J. 2015. The importance of blue light for leaf area expansion, development of photosynthetic apparatus, and chloroplast ultrastructure of Cucumis sativus grown under weak light. Photosynthetica, 53(2): 213-222.

Way D A, Stinziano J R, Berghoff H, et al. 2017. How well do growing season dynamics of photosynthetic capacity correlate with leaf biochemistry and climate fluctuations? Tree Physiology, 37(7): 879-888.

Xing A, Gao Y, Ye L, et al. 2015. A rare SNP mutation in Brachytic2 moderately reduces plant height and increases yield potential in maize. Journal of Experimental Botany, 66(13): 3791-3802.

Xiong D, Wang D, Liu X, et al. 2016. Leaf density explains variation in leaf mass per area in rice between cultivars and nitrogen treatments. Annals of Botany, 117(6): 963-971.

Xu J Z, Yu Y M, Peng S Z, et al. 2014. A modified nonrectangular hyperbola equation for photosynthetic light-response curves of leaves with different nitrogen status. Photosynthetica, 52(1): 117-123.

Ye Z P. 2007. A new model for relationship between irradiance and the rate of photosynthesis in Oryza sativa. Photosynthetica, 45: 637-640.

Ye Z P, Suggett D J, Robakowski P, et al. 2013. A mechanistic model for the photosynthesis-light response based on the photosynthetic electron transport of photosystem II in $\mathrm{C}_{3}$ and $\mathrm{C}_{4}$ species. New Phytologist, 199: 110-120.

Zhu J J, Tremblay N, Liang Y L. 2012. Comparing SPAD and at LEAF values for chlorophyll assessment in crop species. Canadian Journal of Soil Science, 92(4): 645-648.

Zufferey V, Murisier F, Schultz H R. 2000. A model analysis of the photosynthetic response of Vitis vinifera L. cvs Riesling and Chasselas leaves in the field: I. interaction of age, light and temperature. Vitis, 39(1): 19-26.

Zvalinsky V I, Tishchenko P Y. 2016. Modeling photosynthesis and the growth of marine phytoplankton. Oceanology, 56(4): 527-539. 